\title{
The micro-situational context of sexual offences against adult women: Unpacking the role of guardianship intensity in disruption
}

\author{
Alana Cook \\ School of Criminology and Criminal Justice, Griffith University, Australia \\ Benoit Leclerc \\ School of Criminology and Criminal Justice, Griffith University, Australia \\ Danielle M Reynald \\ School of Criminology and Criminal Justice, Griffith University, Australia \\ Richard Wortley
}

Jill Dando Institute of Security and Crime Science, University College London, United Kingdom

Please send correspondence to: Alana Cook, School of Criminology and Criminal Justice, Mt Gravatt Campus, Griffith University, Queensland 4111, Australia; phone: +61 422561 202; email: alana.jayde.cook@gmail.com

Word count: 7783 
The micro-situational context of sexual offences against adult women: Unpacking the role of guardianship intensity in disruption

The current study explores the way guardianship is perceived by offenders and the extent to which it affects the likelihood of disruption in sexual offences against adult females. Specifically, we compare the micro-situational contexts in which sexual offences against adult females are disrupted to those in which these offences are completed. Data on sexual crime events was collected from 138 adult males who were incarcerated for committing a sexual offence against a woman using a self-report questionnaire incorporating a crime-script framework. We found that the presence or availability of a guardian does not guarantee offence disruption. Rather, action taken by the guardian is the critical factor which determines a sexual offender's decision to cease the offence.

Keywords: sexual offending, guardianship, situational crime prevention, offender decision-making 


\section{INTRODUCTION}

Capable guardianship, defined as the presence of others who may have the capacity to supervise and intervene, has typically been acknowledged as serving an important protective function in discouraging property crime offending (e.g. Reynald, 2009, 2011a, 2011b). Recent findings indicate that guardianship may also be an effective mechanism for reducing the incidence (Beauregard \& Leclerc, 2007; Ullman, 2007) or severity (Leclerc, Smallbone, \& Wortley 2015) of sexual offences. Reflected in preliminary self-report data collected from both incarcerated sexual offenders (see Beauregard \& Leclerc, 2007) and sexual assault victims (see Hart \& Miethe, 2008), it has emerged that the presence of persons, other than the offender and victim, heightens sexual offenders' perception of their risk of detection. It has been estimated that third-parties are present in at least one-third of all sexual offences involving adult female victims (Beauregard \& Leclerc, 2007; Chiu \& Leclerc, 2019; Hart \& Miethe, 2008; Tark \& Kleck, 2014). Guardianship may therefore be a specific situational feature which can be extended or increased to prevent the escalation of sexual offence severity or block the opportunity for sexual offending altogether.

Research on guardianship has shown that while the availability or presence of guardians plays a fundamental role in crime prevention and control, the effectiveness of guardianship can be enhanced when guardians actively monitor or supervise, and intervene when they witness certain types of crime or related event (Reynald, 2011b). This paper extends criminological research with a first-time examination of the extent to which guardianship intensity affects the likelihood of the disruption of sexual offences against adult females, using data provided by sex offenders themselves. The micro-situational and contextual factors that characterize completed versus non-completed (i.e. offenders were stopped or discouraged during the offence) sexual offences are compared, revealing the importance of situational characteristics, 
such as guardianship intensity and age of guardian, in conceptualizing and enacting capable guardianship in sexual offences.

\section{Theoretical Orientation of Guardianship}

The mechanism of guardianship was introduced as one of the three fundamental elements underpinning Cohen and Felson's (1979) Routine Activity Approach. Departing from traditional explanations of crime which emphasize individual offender characteristics, the routine activity approach takes an opportunity perspective and views criminal behavior to be a normal by-product of people's everyday non-criminal movements or routines within society. At its core, the routine activity approach aligns with the idea that people's structured daily movements influence both the availability of viable criminal opportunities and the likelihood these opportunities will be exploited (Cohen \& Felson, 1979). When people modify their routine behaviors they subsequently influence the spatial and temporal intersection of the three necessary conditions of criminal activity. These are a motivated offender who has the ability to commit a crime, a person or object which provides a suitable target for the crime, and the absence of a capable guardian who can directly or indirectly discourage or interrupt crime commission (Cohen \& Felson, 1979).

First defined by Felson and Cohen (1980:392) as "any spatio-temporally specific supervision of people or property by other people which may prevent criminal violations from occurring", guardians are typically viewed as the actors in the crime event who protect or defend targets or victims. The original work on guardianship conceptualized guardians as everyday citizens who could protect targets while carrying out their routine behaviors within society (Cohen \& Felson, 1979). A guardian can therefore be any person who is available when an offender in search of crime opportunities comes into contact with potential crime targets. The emphasis on regular citizens as guardians, as opposed to people who operate in a formal crime control capacity, stems from the fact that they are more likely to be available at places 
than formal police (Cohen \& Felson, 1979; Felson, 1998). As a result, it is assumed that regular citizens will more readily be able to monitor a situation when necessary, increase the possibility of detection and/or apprehension for the offender and therefore reduce the likelihood of criminal behavior (Felson, 1998).

\section{Guardianship and Situational Crime Prevention}

Guardians discourage opportunities for crime by triggering the situational crime prevention (SCP) strategy of increasing risk (Clarke, 1997). SCP shifts the focus from social and psychological causes of crime to instead embrace the role of the immediate environment in enabling deviant opportunities (Clarke, 1980). By manipulating those factors within the immediate environment which create or enable criminal opportunities, situational crime prevention seeks to alter offender decision-making so that fewer attractive and available opportunities for offending are perceived. It is in this way guardianship acts as a specific situational feature which can be extended/increased to impede the necessary conditions for crime and ultimately block opportunities for offending (Clarke, 1980; 1997).

\section{Conceptual Developments in Guardianship}

Developments within the routine activity approach have resulted in the expansion of the crime controller role to extend beyond the guardian. Guardians are one of three types of crime controllers, along with handlers and place managers (Clarke \& Eck, 2003; Eck, 2003). From the perspective of crime prevention, handlers are tasked with the responsibility of supervising potential offenders and often assume the role of a parent, spouse, or employer (Eck, 2003). Managers are those people responsible for supervising places or the potential settings of crime events. Common examples include bar staff, landlords and store clerks (Eck, 2003). The final type of controller, the guardian, refers to those individuals tasked with protecting potential targets or victims. This role can be performed by anyone including family members/friends, intimate partners, strangers and occasionally public or private security 
(Clarke \& Eck, 2003; Felson, 1995). Together, controllers can exert influence over the offender, victim and/or situation and facilitate crime prevention.

Another significant advancement which has contributed to the evolving definition and theoretical development of guardianship is Reynald's (2009) Guardianship in Action (GIA) model. This model was introduced to illustrate the multi-dimensional conceptualization of guardianship. It was applied to examine guardianship at the property level and used direct field observations to validate that there are four critical stages of guardianship intensity - invisibility, availability, capability of monitoring, and intervention when necessary. At the core of this model is idea that while the active behaviors of monitoring/supervision and intervention are necessary determinants of capable guardianship in some instances, it is potential guardianship at the availability stage which remains the most critical dimension (Cohen \& Felson, 1979; Felson, 2010). This is because if no-one is available, then the subsequent stages of monitoring, and intervention are not possible and active guardianship cannot be enacted.

This distinction the GIA model makes between potential or inadvertent guardianship and active or purposeful guardianship (see Reynald, 2011b) is particularly relevant to our understanding of how guardianship might protect against the sexual abuse of adult females. In looking at how varying expressions of guardianship intensity affect crime rates, the model suggests that while the mere presence of a guardian may discourage some offending from occurring (see Leclerc, Smallbone \& Wortley 2015) or assist in solving sexual offences (Chiu \& Leclerc, 2019), increased levels of intensity should be related to lower levels of crime and disorder (Reynald, 2009). If a controller (guardians or handlers in particular) chooses to intervene, for example, this should theoretically increase the likelihood of a sexual offence being disrupted - particularly if this intervention is direct and immediate (Reynald, 2011b). It is this premise which underpins the widespread implementation, across U.S. college campuses, of bystander behavior training programs. These programs seek to increase bystander efficacy 
by promoting the distinction between passive bystanders, whose inaction may encourage continuation of the offence, and active bystanders, who are willing to take action and are capable of interrupting the offence, in (see, for example, Banyard, Plante \& Moynihan, 2004). Drawing on both the intrapersonal (individual) and contextual (situational) differences which are observed in the literature surrounding bystander responses to sexual offences (see Cook \& Reynald, 206), the men and women who engage with these programs are provided tailored strategies for intervening safely and effectively in situations they believe are leading to sexual violence. By circumventing the common barriers which impact on individual decisions to progress from monitoring to intervention, bystander programs use a community approach to guardianship as a means of reducing the occurrence of dating and sexual violence on campus.

\section{Past Research on Impact of Guardianship in Sexual Offences}

This burgeoning adoption of the bystander approach to the problem of sexual violence in the U.S. represents a critical development in what we know about the capacity of guardians for sexual violence prevention. College-aged samples that engage with these programs appear more confident in their ability to recognize and intervene in risky situations (see Coker et al., 2011; Banyard, Moynihan \& Plante, 2007), providing powerful support for the role potential guardians may play in proactively disrupting sexual violence. However, evaluations of these programs have not typically been able to speak to the efficacy that empowering guardians has for the actual prevention of sexual violence in practice (Coker et al., 2015). This is exacerbated by the fact that relatively little attention has been given in empirical literature to the availability of guardians and the varying levels of guardianship intensity that may be present during sexual crime events involving adult female victims. Table 1 provides a summary of the empirical studies that have examined guardianship in sexual offences against adult females.

\section{TABLE 1 HERE}


With a few exceptions (see for e.g. Chiu \& Leclerc, 2016), most existing empirical research suggests that potential guardians are available in 20 to 40 percent of sexual offences involving adult female victims (Beauregard \& Leclerc, 2007; Hart \& Miethe, 2008; Tark \& Kleck, 2014). Moreover, it is consistently reported that the odds of rape completion appear to decrease in situations where third-parties, defined as any person other than the offender or victim, are present although these studies have typically not gone into detail about the intensity of these third-parties guardianship (e.g. whether they are located in the same room or another room) (Cook \& Reynald, 2016). For instance, Hart \& Miethe (2008) identified that victims typically perceived third-party intervention to be helpful in de-escalating an incident of sexual assault but there was no explanation provided as to what this intervention entailed or how many third-parties witnessed but did not intervene.

In theory, these findings support the broad adoption of increased or extended guardianship as a strategy for stopping or discouraging the sexual victimization of adult females. In practice, however, we know the impact of guardianship is likely to be contingent on the individual offender in question and the unique way they perceive, interpret and interact with their immediate environment. This is because situational prevention approaches such as guardianship are built on the assumption that crime is a product of a person-situation interaction (Wortley, 2012). Applied to offender decision-making, the choice to desist in the presence of a guardian forms part of a sequence of events (i.e. crime script) in which the situational dynamics act as choice-structuring properties (Wortley, 2012). These impact the offender's assessment of risk and difficultly and in turn influence how they respond to guardianship as a situational prevention mechanism. To therefore determine exactly how guardianship affects offender-decision making and offence outcome, it is critical scholars consider the microsituational or contextual factors which surround the crime event - a point which has been largely neglected in the adult-victim sexual offending literature. 


\section{THE CURRENT STUDY}

It is clear guardianship holds enormous potential for sexual offence prevention and crime in general but there are important gaps in our knowledge which persist. Perhaps most critically, is that the infancy of guardianship research within the context of sexual offences means very little is known about real-life conditions under which guardianship, in interaction with other situational mechanisms, is/is not effective in deterring sexual crimes against adult women. This makes it difficult to draw any robust conclusions with regards to the practical role that regular citizens may play in disrupting, and minimizing the severity of these offenses. The second gap is that empirical findings have been largely descriptive with a focus on simple, binary observations of guardianship presence versus absence. This means that knowledge is lacking about the impact of the characteristics of the guardians available in sexual offences, the circumstances under which they are available, and the level or intensity of guardianship which they provide. A final related benefit is the theoretical advancement of the concept of guardianship in criminology and most specifically, the critical nuance to consider between the impact of a person nearby on crime and a person who actually intervenes to interrupt crime.

With these gaps in mind, the overarching aim of the current study is to unpack the role of guardianship in disrupting sexual abuse against women using a micro-situational analysis of self-reported sexual crime events. Three questions guide the research:

1) What role does guardianship, at its broadest definition, play in disrupting sexual offending against women?

2) To what extent do situational guardianship characteristics (age of guardian, relationship between guardian and offender/victim, offense location) affect the likelihood of a sexual offence against a woman being disrupted? 
3) How and in what ways does the intensity of guardianship (nearby guardians, witness guardians, intervening guardians) affect the likelihood of a sexual offence against a woman being disrupted?

It is important to note here that most existing research examining situational prevention of sexual offending has measured crime event outcome by the intrusiveness of sexual behaviors (Leclerc et al., 2011; Leclerc et al., 2015). Being able to determine what disrupts or stops the commission of a sexual offence, from the perspective of those who commit the crime, represents a significant advancement to current knowledge. To our knowledge, this study is also the first to unpack the specific micro-situational contexts which characterize capable guardianship in the context of sexual offences involving adult women victims.

\section{METHOD}

\section{Sample}

A total of 145 adult males who were incarcerated for having committed a contact sexual offence against a woman (16 years or older) participated in this study. Applying this definition allowed for the inclusion of sexual acts such as fondling, penetration and oral contact while excluding non-assaultive behaviors such as exhibitionism, or voyeurism. All participants gave voluntary informed consent and were recruited from correctional centers in Queensland, Victoria, and Northern Territory, Australia. To avoid limitations associated with poor memory recall, only the most recent offence committed by each participant was included in final analyses, regardless of whether this was or was not the offence for which they were incarcerated. The final sample used for this study comprised 138 participants ${ }^{1}$.

\footnotetext{
${ }^{1}$ Three participants were deleted from analyses as they reported both a disrupted and completed offence, but it was not possible to determine the temporal ordering of these events. Another four offenders did not respond to the questions on guardianship. These cases were also deleted.
} 
On average, participants were 29.2 years of age at the time of their most recent offence $(S D=12.79)$. Almost two-thirds identified as either Aboriginal $(48.9 \%)$ or Australian Torres Strait Islander (12.1\%) with other participants either Australian born non-Aboriginal (27.7\%) or born in another country $(11.3 \%)$. Just over a fifth of participants reported the perpetration a sexual offence prior to the one discussed in this study (22\%), and most did not achieve higher than a high-school education $(80.1 \%)$. A total of $31.2 \%$ of participants were single at the time of the offence and $32.6 \%$ were without employment. Almost two-thirds of offenders $(65.2 \%)$ were currently, or had previously, participated in a treatment program for sexual offenders with Corrective Services at the time of participation in the study.

\section{Procedure}

This study used offender self-report data from a larger project examining how sexual offenders directly perceive and have experienced situational prevention techniques in their offending. The aim of the project was to better understand the effectiveness of situational prevention for preventing sexual violence and abuse. Eligible offenders were first identified by Queensland Department of Corrective Services, NT Department of Correctional Services, and Department of Justice and Regulation, Victoria and recruitment by the research team occurred over the period of 2014 through 2017 inclusive. Eligible offenders were approached by a member of the research team and invited to complete a confidential self-report questionnaire incorporating a crime-script framework (Cook, Reynald, Leclerc, \& Wortley, 2018). The purpose of the instrument was to break down the crime-commission process of sexual offenders, in order to observe the way SCP techniques factor into offender-decision making. Participants were asked to recall the most recent non-completed and/or completed offence which they committed, and were presented with a series of self-report questions which captured information on situational aspects such victim characteristics, offender-victim relationship, and location of the offence, in addition to the modus operandi strategies adopted prior to, during, 
and following the commission of the sexual offence. Using this template, we were able to break down the crime-commission process of sexual offenders and observe not only which situational crime prevention techniques work and which do not, but also the micro-situational context which characterized their most offending.

Involvement in the study was voluntary with each participant asked to provide written consent prior to their participation. In providing consent, participants were assured their anonymity would be safeguarded with the information they provide used for research purposes only. A total number of 138 crime events involving sexual contact with an adult female were analyzed.

\section{Variables}

The key independent variable in this study was the level of guardianship intensity during the commission of the sexual offence. This was measured in three ways; (1) a guardian who was available, but not visible - e.g. nearby in another room (2) a guardian who was available, and visible - e.g. a witness, or (3) a guardian who was available, visible, and made the choice to intervene. Each guardian ${ }^{2}$ reported by a participant was captured only once in the data against the highest level of guardianship intensity which best defined their role in the event. To ensure the variable was captured in this way, participants were first asked if they were aware of the presence of someone who was visible as a witness and intervened (i.e., the highest level of guardianship intensity) $(0=n o ; 1=y e s)$. If yes, they were then asked to identify who intervened (e.g., offender's biological child, adult friend of the victim, stranger), the action they took (i.e., direct physical intervention, direct verbal intervention, indirect intervention) and if the intervention was effective in either stopping or discouraging sexual contact with the victim therefore leading to a non-completed offence $(0=n o ; 1=y e s)$.

\footnotetext{
${ }^{2} 2$ Co-offenders (i.e. accomplice of the offender) were not included in this definition of a guardian.
} 
Participants were next asked if they were aware of any person who was present/available, and visible as a witness, but did not intervene $(0=n o ; 1=y e s)$. If yes, they were asked to identify who this guardian (i.e. witness) was and if the witness was effective in either stopping or discouraging sexual contact with the victim $(0=n o ; 1=y e s)$.

Finally, participants were asked if they were aware of any other people who were present/available, but not visible during the sexual contact $(0=n o ; 1=y e s)$. An example of this would be a guardian who was in another room of the house. If yes, they were asked to identify who this nearby person was and if their availability was effective in either stopping or discouraging sexual contact with the victim $(0=n o ; 1=y e s)$.

Three additional variables related to offender decision-making and sexual offence outcomes were also extracted from the self-reported responses. These were the offender-victim relationship ( $0=$ non-stranger, $1=$ stranger $)$, location of the offence $(0=$ outdoors, $1=$ indoors $)$, and if the victim engaged in any form of resistance $(0=n o, 1=y e s)$ were also extracted from the data. These variables were coded as dichotomous.

The dependent variable of interest in this study was outcome of the sexual contact. Specifically, we were interested in whether the offence was disrupted $(0=n o, 1=y e s)$. For consistency, we defined a disrupted offence as an event where the offender was either stopped or discouraged while in the process of initiating the sexual contact, or stopped or discouraged during the sexual contact therefore leading to a non-completed offence. Descriptive statistics and definitions for all variables are provided in Table 2.

\section{TABLE 2 HERE}

\section{ANALYTIC STRATEGY}

The main purpose of this study was to use offenders' self-reported criminal experiences to explore whether offenders perceive guardianship as important for disrupting adult-victim sexual offences in real-life abuse settings. The analysis of data is performed in three stages. 
The first stage consisted of using conjunctive analysis of case configuration (CACC) to explore the dominant situational contexts leading to a sexual offence having a disrupted outcome. In the study of crime events, CACC is used to understand the unique situational contexts in which a certain outcome is more likely or less likely to occur and the varying configuration of variables which define these contexts (Miethe, Hart, and Regoeczi, 2008). Given the exploratory nature of the research, CACC was preferred as the first stage of this analysis as we could use it to unpack the broad situational contexts surrounding reported sexual offences and the overarching factors which emerge as most likely to lead to a disrupted outcome.

In this research specifically, we were interested in whether there is a relationship between a disrupted crime outcome and offences in which there was at least one available guardian, irrespective of whether the guardian was nearby and not visible, a witness, or a person who intervened. As a result of the small sample size, we limited the number of independent variables in CACC to the four deemed most relevant to the study aims and research questions ${ }^{3}$ (guardianship, offender-victim relationship, location of offence, victim resistance). Together, these represent a total of 16 possible distinct situational contexts. Logistic regression was then completed to determine the strongest predictors of sexual offence disruption. To control for key correlates that may impact on the outcome of sexual contact, guardianship (again, irrespective of whether the guardian was nearby, a witness or intervened) was introduced first in Model 1 followed by the other situational variables in Model 2.

In the second data analysis stage, we explored how the association between guardianship and offence disruption is influenced by other situational characteristics. Descriptive statistics were used to identify the age of the guardian, (child or adult), their relationship with the offender and/or victim (known person or stranger), and their location at

\footnotetext{
${ }^{3}$ The four variables were selected based on their expected association with the outcomes, and the absence of any extreme splits between the two levels.
} 
the time of offence (indoors or outdoors) across disrupted offences compared to completed offences.

Finally, in the third stage, we explored how the association between guardianship and offence disruption is influenced by the intensity of guardianship. Using only the sexual crime events which were reported to involve a guardian, a chi-square test for independence was first used to explore if there is a significant association between guardianship intensity and sexual offence disruption. The independent variable (guardianship intensity) was dummy coded into low intensity (0) and high intensity (1) to represent this contrast. Chi square analysis was also used to determine if the likelihood of a disrupted sexual offence outcome varied by location, offender-victim relationship or resistance from the victim. Finally, we used descriptive statistics to capture how guardianship intensity differs between completed and disrupted sexual offences. To understand if, and how, these potential guardians responded to witnessing the sexual contact, the types of intervention strategies used were also examined. In particular, we looked at the use of indirect methods of intervention (e.g. alerted another person, calling the police), direct verbal methods of intervention (e.g. shouted at the offender to stop), direct physical methods of intervention (e.g. pushed the offender away) or a combination of the three.

\section{RESULTS}

\section{Stage 1: Relationship between Guardianship and Sexual Offence Disruption}

Respondents were aware of a guardian in $35.5 \%$ of the sexual offences reported (see Table 2). Of the events where a guardian was reported $(n=49)$, approximately $65.3 \%(n=32)$ involved a guardian who was available but not visible (i.e. a nearby person), $2 \%(n=1)$ involved a guardian who was available, and visible - e.g. a witness, and $32.7 \% \quad(n=16)$ involved a guardian who was available, visible, and made the decision to intervene. To therefore understand the role of guardianship at its broadest definition in the disruption of sexual offences against women (i.e. the presence of any guardian, irrespective of their intensity), we use the 
exploratory method of CACC to identify the distinct situational contexts in which sexual offences are most likely to be disrupted (Table 3 ). While all 16 case configurations were empirically observed, only those combinations with at least five cases within them were retained. This cut-off is consistent with the precedence established in previous studies (Mieczkowski \& Beauregard, 2010; Leclerc \& Cale, 2015). Profiles were then numerically ordered according to their relative prevalence of a disrupted offence outcome. A likelihood level, calculated using the same method again as Mieczkowski and Beauregard (2010) and Leclerc and Cale (2015), was finally determined to indicate the relative likelihood of offence disruption in that context. In total, five profiles were found to represent a high likelihood of offence disruption. The configuration of the most dominant context, in which $100 \%$ of offences were disrupted, was characterized by an outdoor assault committed against a known person, where the victim used either physical or verbal resistance and a guardian was available. With all other categories remaining the same, the availability of guardianship increased the likelihood of disruption by $20 \%$.

\section{TABLE 3 HERE}

Comparing the nature of case configurations with a high likelihood of disruption to those with a low likelihood of disruption indicates guardianship, victim resistance, and offence location are all highly discriminatory with respect to offence outcome. More than half of the profiles with a high likelihood of disruption involved guardianship (3 out of 5), victim resistance (4 out of 5) and the offence occurring outdoors (4 out of 5) suggesting a strong link between these situational factors and a disrupted offence outcome. In contrast, guardianship and victim resistance were present in only one-fifth of profiles with a low likelihood of disruption and an outdoor location arose in only two out of five contexts with a low likelihood of disruption. 
To build on this analysis, Table 4 reports the results of a logistic regression analysis performed on offence outcome. This was done to differentiate the impact of guardianship from the other theoretically relevant situational variables and identify the strongest predictors of offence disruption. Similar to what emerged in CACC, Model 1 indicates that an available guardian (nearby, witness, or intervention) increases the likelihood of the offence being disrupted $(\Psi=3.27)$. This result remains significant when victim resistance, offender-victim relationship and offence location are introduced in Model 2. In the second model, victim resistance is also a significant predictor suggesting that when victim resistance occurs the offence is again more likely to be disrupted.

\section{TABLE 4 HERE}

\section{Stage 2: Micro-Level Relationship between Situational Guardianship Characteristics and Sexual Offence Disruption}

This positive association between available guardianship and sexual offence disruption indicates that guardians may play a role in preventing the sexual abuse of adult females. To tease out the nuances of this association, the second stage of analysis explores whether this relationship is impacted by the characteristics of the guardian and the guardianship intensity they provide.

Descriptive statistics were used to determine if the situational guardianship characteristics (adult compared to child, relationship between guardian and offender/victim, indoors compared to outdoors) affect the likelihood of a sexual offence against a woman being disrupted. Figure 1 presents the characteristics of the guardians reported during disrupted offences according to their age, relationship with the offender and/or victim, level of guardianship intensity, and location.

FIGURE 1 HERE 
In the context of disrupted offences, the majority of guardians were adults (i.e. 17 years or older) with the highest likelihood being adults who were nearby (28.5\%), followed by adults who intervened $(25.4 \%)$. There were no guardians in disrupted offences who witnessed the event but chose not to intervene. Looking at the relationship between adult guardians and the offender and/or victim in these disrupted scenarios shows that the guardians who were nearby, but not visible, were most often known to either the victim or offender. In comparison, the guardians who witnessed and intervened in disrupted events were more often strangers. Turning attention to the location in which these guardians were available shows that, irrespective of their relationship with the offender and/or victim, nearby adults in disrupted offences were typically indoors but adults who intervened in disrupted offences were predominantly outdoors.

With regards to the types of potential guardians available in completed sexual offences, Figure 2 shows that children were reportedly present in almost as many completed offences as adult guardians. Most guardians in completed offences were nearby with the majority of nearby adults and all nearby children known to the offender and/or victim. These known guardians in completed offences were also always encountered in an indoor setting while the smaller number of stranger guardians in completed offences, who in all cases were nearby adults, were only reported in outdoor settings.

FIGURE 2 HERE

\section{Stage 3: Micro-Level Relationship between Intensity of Guardianship and Sexual Offence}

\section{Disruption}

The third stage of the analysis looks at the extent to which the intensity of guardianship affected the likelihood of a sexual offence against a woman being disrupted. Given there was only one incident which involved a witness who did not intervene, 'high intensity' guardianship was defined as guardians who witnessed and/or intervened, and 'low intensity' guardianship 
was defined as guardians who were nearby, but not witness to the event. For the three events which involved a person nearby and another person who witnessed and intervened, the level of guardianship was coded as high intensity as each of these three offenders reported that the intervention, rather than the presence of the nearby person, was what led to their decision to discontinue the offence.

A chi-square test for independence was first used to explore whether there was a significant association between guardianship intensity and disrupted offence outcome. As depicted in Table 5, results indicated a statistically significant relationship between the two variables, $\chi 2(1, \mathrm{~N}=49)=8.73, \mathrm{p}=.01$. Chi-square analyses were also conducted assess if the likelihood of a disrupted sexual offence outcome varied by location, offender-victim relationship or resistance from the victim. In contrast to the earlier analysis in Step 1 which involved all reported sexual offences, these results showed that for the sexual offences committed in the presence of a guardian $(n=49)$, there was no significant association between victim resistance and offence disruption, but there was a significant association between offence location and offence disruption (see Table 5).

\section{TABLE 5 HERE}

To further unpack the relationship between guardianship intensity and disrupted offence outcome, descriptive statistics were used to determine how guardianship intensity relates to sexual offence disruption. Figure 3 shows that it is high intensity guardianship that increases the likelihood of the offence being disrupted. While a similar number of disrupted compared to completed offences involved a person nearby, just over a quarter of disrupted sexual offences involved a guardian who was available, visible, and made the choice to intervene compared to zero completed sexual offences. Moreover when the participants who reported intervention by a witness were asked what impact this intervention had, all but one indicated that the intervention was effective in stopping or discouraging them from continuing with the sexual contact. 


\section{FIGURE 3 HERE}

An analysis of how guardians intervened show that $58.8 \%$ engaged in verbal direct intervention (see Figure 4). This was defined as verbal actions, such as shouting, which are aimed at directly disrupting the offence in progress. The second most common reaction was physical direct intervention (41.2\%) which typically involved the guardian physically confronting the offender (e.g. pushed them off the victim). An indirect intervention was the least common reaction of guardians $(29.4 \%)$ and often occurred in conjunction with a direct response.

\section{FIGURE 4 HERE}

\section{DISCUSSION}

Despite the importance it offers for crime prevention there has been little empirical attention given to the effect of guardianship on sexual offending. Consequently, there is limited understanding of what guardians contribute to the prevention of sexual offences against adult women in practice and how and/or if the impact of guardianship on offender decision-making varies across dynamic situational contexts. This study builds on these gaps by exploring sexual offenders' direct experiences of guardianship focusing on the most recent disrupted or completed sexual offence they committed against an adult female victim. Overall, results confirm that guardianship is a situational factor which sexual offenders encounter, and respond to, in the context of their criminal decision-making.

\section{The Overarching Importance of Guardianship for Sexual Offence Disruption}

Consistent with current approximations of guardianship availability (see Beauregard \& Leclerc, 2007; Hart \& Miethe, 2008; Tark \& Kleck, 2014) we found that offenders were aware of a guardian being present in just over a third of sexual offences. However, further examination showed that guardianship at its broadest level of abstraction was strongly and 
positively associated with a disrupted but not completed offence outcome. Moreover, three of the five contexts with a high likelihood of disruption identified in the conjunctive analysis involved a guardian.

Taken together, these findings indicate that the mechanism of guardianship is a fundamentally important factor in sexual offence disruption. However, because guardians were also available in a number of completed offences (i.e., one of the CACC contexts with a low likelihood of disruption involved a guardian), these analyses similarly suggest that the mere availability/presence of a guardian does not guarantee disruption. One possible explanation, which appears supported by the current study, is that the effectiveness of guardianship for sexual offence prevention is highly context-specific. We argue that while it is important a guardian is available, the most critical factors from the perspective of offenders are who the guardian is what the guardian is doing.

\section{The Importance of the Situational Guardianship Characteristics}

Results show that the guardians available during disrupted offences were characteristically different from the guardians available during completed offences. Perhaps most critically, we found that the majority of the guardians available during disrupted sexual offences were adult/s (i.e. 16 years or over), while almost half the people reportedly available in completed offences were children. In addition, we identified that when children were present during offenses they were always nearby (i.e. not close enough to witness), always indoors (i.e. the offender or victim's home) and always known to the offender and/or victim. By comparison, the adult guardians were often in a position where they could witness and intervene, with these actions typically occurring in outdoor settings (i.e. a park or a street). A likely explanation for this is the increased surveillance opportunities generated by the physical context of outdoor space (Reynald, 2011a). The finding that offence location is statistically 
associated with offence disruption when the event involves at least one guardian provides tentative support for this.

The distinction in age between the guardians in disrupted compared to completed offences highlights an important issue in terms of how capable guardianship within sexual offending can be conceptualized. It is likely that adults and children are categorically different from one another in their capacity as capable crime prevention agents. According to offender accounts within this study, adult guardians typically expressed the three components of capable guardianship identified by Reynald (2010). These are (1) willingness to supervise, (2) ability to detect potential offending, and (3) willingness to intervene. In no situations however, was a child guardian reported to even witness the offence. This suggests that compared to adults, children do not have the same opportunities and/or capabilities when it comes to intervention. This conflicts with most of the current work which evaluates the role of guardians in sexual offending against women as these studies generally adopt a broad definition of guardianship where guardians of any age group are collapsed into a single guardianship category (Chiu \& Leclerc, 2016; Hart \& Miethe, 2008). A similar analytic approach is noted in the child sexual offending literature because of the difficulty in specifying who the guardian is based on the data available (Leclerc et al., 2015; McKillop et al., 2015). This points to the theoretical gaps to fill in this area of research and the importance of recognizing the distinction between guardians who are capable compared to guardians who are merely available.

Drawing these comments together, our findings contribute to the debate about whether children should be considered equal to adults when promoting the significance of capable guardianship for the prevention of sexual violence against women. While it is clear children can act as potential guardians since disclosure from them remains possible, the convergence of their developmental vulnerabilities with the physical settings in which they are typically present, diminishes the likelihood that they will be in a position to supervise and/or intervene/disclose (Leclerc et al., 2015). As our findings suggest, if a child is available but 
they don't have the opportunity to engage in these action dimensions, they may subsequently lack capability in terms of disrupting opportunities for sexual offending (Reynald, 2009). This implies that capable guardianship in the context of sexual offending against a woman, depends not just on who the guardian is, but also what the guardian does.

\section{The Micro-Situational Importance of What the Guardian Does}

The results of this study show that sexual offences where the guardian witnessed and/or intervened were significantly more likely to be disrupted. This increased likelihood of disruption was also observed irrespective of the type of witness reaction - i.e. both direct and indirect interventions had an effect. In contrast, guardians who were available but not visible (e.g. nearby in another room of the house) did not appear to have any significant impact on offence disruption. Given recent research by Liebst, Heinskou, and Ejbye-Ernst (2018) which reports a relatively low risk of personal injury to third-parties who directly intervene in violent situations, we argue for the emphasized importance of action over availability - when safe to do so - as a key factor facilitating sexual offence disruption.

Taken together, these findings show that the disruption of sexual offending against women is related to the intensity of guardianship. However, unlike property crime where it established that availability is the critical dimension (Reynald, 2009), our results suggest that in the context of sexual offending against women, and perhaps interpersonal crime more broadly, it is the action dimensions of guardianship which are most important. This suggests that a higher intensity of guardianship may be required to disrupt opportunities in interpersonal crime compared to what is required to disrupt opportunities in property crime. Considering that the majority of active guardians were also in an outdoor setting and there was a significant association between offence disruption and offence location when a guardian was present during the event, our results similarly suggest that in the context of sexual offending, this transition to capable guardianship may be, in part, determined by the immediate environment 
in which the offence occurs (Reynald, 2009; 2011a). In settings where there are clearer lines of sight and better visibility of space, the likelihood of guardian witnessing and then potentially intervening in criminal behavior, is much higher.

Consistent with our first analysis (see Table 4), Guerette \& Santana's (2010) findings indicated that both victim resistance and the presence of a person nearby were effective in preventing rape. However, our additional analysis on the intensity of guardianship specifically revealed that what matters the most in disrupting sexual offences is not the mere presence of a person nearby and/or victim resistance but the fact that the guardian witnesses and/or intervenes during the offence. This observation suggests that when a capable guardian is present (e.g. someone who actually intervenes), the outcome of the assault may be unaffected by whether or not the victim resists. However, when a sexual offence opportunity intersects with the absence of guardianship, action by the victim becomes much more critical for disruption. This observation is not entirely surprising as we know from previous literature that rape avoidance has consistently found to be associated with the performance of self-protective actions (ClayWarner, 2002; Fisher, Daigle \& Cullen, 2010; Guerette \& Santana, 2010; Ullman, 2007). From a situational perspective, this interaction also makes sense because if the offender and victim are alone, it is not likely a guardian will arrive at the location and witness the situation. As such, while the presence of a witness guardian may neutralize the need for a victim to respond, if there is no guardian available the only remaining opportunity for disruption is the selfprotective action which the victim takes themselves (e.g. verbal or physical resistance).

What these findings also indicate is that the presence of guardianship may neutralise, to some extent, the risk of injury to a victim who fights back against their offender. In making this point however it is important to recognise that the escalation of violence in response to victim resistance operates within a coercive interchange where it is the initial attack strategy of the offender that often predicts the reaction of the victim (Balemba, Beauregard \& 
Mieczkowski, 2012). As such, while guardianship intervention is arguably a safer option for victims than self-protection and it has been established in prior research that third-parties who directly intervene are at a relatively low risk of personal injury (see Liebst et al., 2018), it is still extremely important that guardians are encouraged to intervene in a way that accounts for any potential risk to both themselves and the victim. The fact that this research found direct, verbal interventions were reported as the most common type of guardian response suggests that guardians may not be required to place themselves in an excessively risky situation (i.e. physically confront the offender) to bring about offence disruption. Actions such as yelling at the offender from a distance or even calling to another person for help appear to sufficiently increase perceived risks. In relation to current research on barriers to bystander intervention, this is a particularly important finding as one of the main reasons bystanders are found to not to help a victim when witness to a sexual assault is due to fear of their own personal safety (Banyard, 2011).

\section{Limitations}

To our knowledge, this study is the first to examine the micro-situational contexts which characterize capable guardianship in sexual offences involving adult victims. As such, we acknowledge that there are some limitations which surround the present findings. First, our study draws on self-report data collected from incarcerated offenders. This may mean that participant responses are subject to a social desirability bias. The responses to guardianship reported in our data may also be characteristically different from those offenders who have not been apprehended because the latter group may employ more sophisticated strategies to overcome situational barriers. We also acknowledge that although clear definitions were provided within the survey instrument, there may also have been some situations in which participants either incorrectly interpreted questions or provided information on a modified version of events (i.e. if the stress experienced during the event meant their attention was 
focused on getting the victim to comply, they may not have been aware of a guardian who was nearby). Lastly, our study is based on a relatively low number of cases with almost two-thirds of recruited participants identifying as either Aboriginal or Australian Torres Strait Islander. While this is likely a reflection of the difficulty in collecting data from a sensitive and difficult to access population and the regions in which participants were recruited, results still need to be interpreted accordingly.

\section{CONCLUSION}

Together these findings show that the disruption of sexual offending against women really depends on who the guardian is, and what the guardian and/or victim are doing. Action, on behalf of the guardian or, if necessary, the victim, appears to be the critical factor which determines a sexual offender's decision to cease the offence. The fact that adults emerge as capable guardians while children do not also ties in with this concept of action, as it shows that the contexts which surround children as guardians restrict their ability to react and respond. While, in part, a reflection of the fact that opportunities for capable guardianship are determined by the physical environment, this finding also promotes the importance of willingness and ability in defining capable guardianship (Reynald, 2010).

This study offers vital insights into what we know about the role of guardians in disrupting or preventing the sexual abuse of women in the first place. By showcasing the importance of adults as capable guardians, and reinforcing the importance of action over availability for sexual offence disruption, our findings illuminate the importance of the microsituational context in operationalizing capable guardianship. They additionally indicate that the capability of guardianship in sexual offences against women is contingent on the perception of the offender. Anything short of a guardian who witnesses the offence does not appear to sufficiently increase the risk of detection sexual offender's associate with the immediate criminal environment. It is clear we need to be a lot more nuanced in defining capable guardianship, specifically in the context sexual offending, which we aimed to accomplish here. 
Whether it is for developing the theoretical concept of guardianship or applying it for prevention purposes, it is essential to differentiate between the guardians who are nearby and those who witness and intervene, and to clearly identify who the guardian is. The nuance that emerged in this study, that is, between the impact of the mere presence of a guardian and the presence of a person who is witnessing or intervening during crime on disruption, proves critical for future research on the effectiveness of guardianship in preventing crime.

Further research in this area, using the victim's perspective of the crime event, would be valuable for building additional knowledge around what guardians can do for victims to most effectively disrupt the situation. For example, victims may perceive certain types of guardians or guardianship responses as more reassuring than others. Moreover, identifying the victim's perspective on situational techniques would emphasize precisely when, during the crime event, guardians are available and at what stages of crime commission guardianship needs to be boosted. Considering we found preliminary evidence to suggest any intervention action by the guardian (e.g. indirect and direct) effectively disrupted the sexual offence, it would also be worthwhile examining the micro-actions of guardians using a much larger sample. This would help us to understand the extent to which a guardian's actions interact with situational features and, in turn, inform the development of pro-active and practical model of guardianship intervention (see Cook \& Reynald, 2016, for a preliminary model of bystander action). Moving forward, we argue that shifting focus to the micro-situational context of the offence will offer the most critical insights into the role regular citizens can play in disrupting, and ultimately preventing, the occurrence of sexual and violent offending, more broadly.

\section{Funding}

This work was supported by the Australian Research Council (DP130100501).

\section{References}


Balemba, S., \& Beauregard, E. (2013). Where and when? Examining spatio-temporal aspects of sexual assault events. Journal of Sexual Aggression, 19(2), 171-190.

Balemba, S., Beauregard, E., \& Mieczkowski, T. (2012). To resist or not to resist? The effect of context and crime characteristics on sex offenders' reaction to victim resistance. Crime \& Delinquency, 58, 588-611.

Banyard, V. L. (2011). Who will help prevent sexual violence: Creating an ecological model of bystander intervention. Psychology of Violence, 1(3), 216-229.

Banyard, V. L., Moynihan, M. M., \& Plante, E. G. (2007). Sexual violence prevention through bystander education: An experimental evaluation. Journal of Community Psychology, 35(4), 463-481.

Bart, P., \& O'Brien, P. H. (1985). Stopping rape: Successful survival strategies. New York: Pergamon Press.

Beauregard, E., \& Leclerc, B. (2007). An application of the rational choice approach to the offending process of sex offenders: A closer look at the decision-making. Sexual Abuse: A Journal of Research and Treatment, 19, 115-133.

Beauregard, E., Leclerc, B., \& Lussier, P. (2012). Decision making in the crime commission process: Comparing rapists, child molesters, and victim-crossover sex offenders. Criminal Justice and Behavior, 39(10), 1275-1295.

Chiu, Y-N, \& Leclerc, B. (2016). An Examination of Sexual Offenses Against Women by Acquaintances: The Utility of a Script Framework for Prevention Purposes. In B. Leclerc and E. Savona (Eds.). Crime Prevention in the $21^{\text {st }}$ Century. Springer.

Chiu, Y-N, \& Leclerc, B. (2019). Predictors and contexts of unsolved and solved sexual offenses. Crime \& Delinquency, 66(9), 1268-1295.

Clarke, R. V., \& Eck, J. E. (2003). Become a Problem-solving Crime Analyst: In 55 Small Steps. London, UK: Jill Dando Institute of Crime Science, UCL. 
Clay-Warner, J. (2002). Avoiding rape: The effects of protective actions and situational factors on rape outcomes. Violence and Victims, 17(6), 691-705.

Clay-Warner, J. (2003). The context of sexual violence: Situational predictors of selfprotective actions. Violence and victims, 18(5), 543-556.

Cohen, L. E., \& Felson, M. (1979). Social change and crime rate trends: A routine activity approach. American Sociological Review, 44, 588-608.

Coker, A. L., Cook-Craig, P. G., Williams, C. M., Fisher, B. S., Clear, E. R., Garcia, L. S., \& Hegge, L. M. (2011). Evaluation of Green Dot: An active bystander intervention to reduce sexual violence on college campuses. Violence Against Women, 17(6), 777796.

Coker, A. L., Fisher, B. S., Bush, H. M., Swan, S. C., Williams, C. M., Clear, E. R., \& DeGue, S. (2015). Evaluation of the Green Dot bystander intervention to reduce interpersonal violence among college students across three campuses. Violence Against Women, 21(12), 1507-1527.

Cook, A., Reynald, D. M., Leclerc, B., \& Wortley, R. (2018). Learning About Situational Crime Prevention From Offenders: Using a Script Framework to Compare the Commission of Completed and Disrupted Sexual Offenses. Criminal Justice Review, 44(4), 431-451.

Cook, A., \& Reynald, D.M. (2016). Guardianship against sexual offences: Exploring the role of gender in intervention. International Criminal Justice Review, 26(2), 98-114.

Deslauriers-Varin, N., \& Beauregard, E. (2010). Victims' routine activities and sex offenders' target selection scripts: A latent class analysis. Sexual Abuse: A Journal of Research and Treatment, 22(3), 315-342.

Eck, J. E. (2003). Police problems: The complexity of problem theory, research and evaluation. In J. Knutsson (Ed.), Problem-Oriented Policing: From Innovation to 
Mainstream. Crime Prevention Studies, Vol. 15 (pp. 67-102). Monsey, NY: Criminal Justice Press.

Fisher, B.S., Daigle, L. E., \& Cullen, F. T. (2010b). Unsafe in the ivory tower: The sexual victimization of college women. Thousand Oaks, CA: Sage Publications.

Felson, M. (1995). Those who discourage crime. In J. Eck \& D. Weisburd (Eds.), Crime and place: Crime prevention studies (pp. 53-66). Monsey, NY: Criminal Justice Press.

Guerette, R. T., \& Santana, S. A. (2010). Explaining victim self-protective behavior effects on crime incident outcomes a test of opportunity theory. Crime \& Delinquency, 56(2), 198-226.

Hart, T. C., \& Miethe, T. D. (2008). Exploring bystander presence and intervention in nonfatal violent victimization: When does helping really help? Violence and Victims, $23,637-651$.

Leclerc, B., \& Cale J. (2015). Weapon use and sexual abuse outcomes: A multivariate and conjunctive analysis of sexual offenses against women. Security Journal, 28(1), 54 70.

Leclerc, B., Smallbone, S., \& Wortley, R. (2015). Prevention nearby: The influence of the presence of a potential guardian on the severity of child sexual abuse. Sexual Abuse: A Journal of Research and Treatment, 27, 189-204.

Leclerc, B., Wortley, R. and Smallbone, S. (2011).Victim Resistance in Child Sexual Abuse: A Look into the Efficacy of Self-Protection Strategies Based on the Offender's Experience. Journal of Interpersonal Violence, 26, 1868-1883.

Liebst, L. S., Heinskou, M. B., \& Ejbye-Ernst, P. (2018). On the Actual Risk of Bystander Intervention: A Statistical Study Based on Naturally Occurring Violent Emergencies. Journal of Research in Crime and Delinquency, 55(1), 27-50.

Marchbanks, P. A., Lui, K. J., \& Mercy, J. A. (1990). Risk of injury from resisting rape. American Journal of Epidemiology, 132(3), 540-549. 
McKillop, N., Brown, S., Wortley, R., \& Smallbone, S. (2015). How victim age affects the context and timing of child sexual abuse: applying the routine activities approach to the first sexual abuse incident. Crime Science, 4(17), 1-10.

Mieczkowski, T., \& Beauregard, E. (2010). Lethal outcome in sexual assault events: A conjunctive analysis. Justice Quarterly, 27(3), 332-361.

Miethe, T.D., Hart, T.C., \& Regoeczi, W.C. (2008). The conjunctive analysis of case configurations: An exploratory method for discrete multivariate analyses of crime data. Journal of Quantitative Criminology, 24(2), 227-241.

Oziel, S., Goodwill, A., \& Beauregard, E. (2014). Variability in behavioural consistency across temporal phases in stranger sexual offences. Journal of Police and Criminal Psychology. Advance online publication.

Planty, M. (2002). Third-party involvement in violent crime, 1993-1999. Washington, DC: U.S. Department of Justice.

Reynald, D. M. (2009). Guardianship in action: Developing a new tool for measurement. Crime Prevention \& Community Safety, 11, 1-20.

Reynald, D. M. (2010). Guardians on guardianship: Factors affecting the willingness to supervise, the ability to detect potential offenders, and the willingness to intervene. Journal of Research in Crime and Delinquency, 47, 358-390.

Reynald, D. M. (2011a). Factors associated with the guardianship of places: Assessing the relative importance of the spatio-physical and sociodemographic contexts in generating opportunities for capable guardianship. Journal of Research in Crime and Delinquency, $48,110-142$.

Reynald, D. M. (2011b). Guarding against crime: Measuring guardianship within routine activity theory. London, England: Ashgate Publishers.

Tabachnick B., \& Fidell, L. (2011). Using multivariate statistics ( $4^{\text {th }}$ ed.). Boston, MA: Allyn and Bacon. 
Tark, J., \& Kleck, G. (2014). Resisting rape: The effects of victim self-protection on rape completion and injury. Violence Against Women, 20(3), 270-292.

Ullman, S. E. (2007). A 10-year update of 'review and critique of empirical studies of rape avoidance' Criminal Justice and Behavior, 34, 411-429.

Ullman, S. E., \& Knight, R. A. (1991). A multivariate model for predicting rape and physical injury outcomes during sexual assaults. Journal of Consulting and Clinical Psychology, 59(5), 724.

Woodhams, J., \& Labuschagne, G. (2012). South African serial rapists: The offenders, their victims, and their offenses. Sexual Abuse: A Journal of Research and Treatment, 24, 131.

Wortley, R. K. (2012). Exploring the person-situation interaction in situational crime prevention. In N. Tilley \& G. Farrell (Eds.), The reasoning criminologist: Essays in honour of Ronald V. Clarke (pp. 184-193). London: Routledge. 
Table 1: Summary of empirical knowledge on guardianship in sexual offences involving adult female victims

\begin{tabular}{|c|c|c|c|c|c|}
\hline Study & Country & Measure of guardianship & Frequency & Population summary & Outcome \\
\hline $\begin{array}{l}\text { Bart and O'Brien (1985) } \\
\text { Data source: Victim self-report data }\end{array}$ & USA & $\begin{array}{l}\text { Environmental intervention during } \\
\text { incident }^{4}\end{array}$ & $12.8 \%$ & $\begin{array}{l}\text { Adult females who were either } \\
\text { raped or avoided rape }(\mathrm{n}=94)\end{array}$ & $\begin{array}{l}\text { Associated with rape } \\
\text { avoidance }\end{array}$ \\
\hline $\begin{array}{l}\text { Marchbanks, Liu and Mercy (1990) } \\
\text { Data source: Victimization data }\end{array}$ & USA & Presence of other persons & Not provided & $\begin{array}{l}\text { Female victims (12 years and } \\
\text { over) of male-perpetrated, single } \\
\text { offender rape and attempted rape } \\
\qquad(\mathrm{n}=851)\end{array}$ & $\begin{array}{l}\text { Reduced odds of rape } \\
\text { completion }\end{array}$ \\
\hline $\begin{array}{l}\text { Ullman and Knight (1991) } \\
\text { Data source: Police reports / Court } \\
\text { testimonials }\end{array}$ & USA & $\begin{array}{l}\text { Environmental intervention during } \\
\text { incident }\end{array}$ & $15 \%$ & $\begin{array}{l}\text { Adult females who were either } \\
\text { raped or avoided rape }(\mathrm{n}=274)\end{array}$ & $\begin{array}{c}\text { Related to less severe sexual } \\
\text { abuse }\end{array}$ \\
\hline $\begin{array}{l}\text { Planty (2002) } \\
\text { Data source: Victimisation data }\end{array}$ & USA & Third-party/s present during incident & $29 \%$ & $\begin{array}{l}\text { Victims (aged } 12 \text { and older) of } \\
\text { single offender non-fatal rape and } \\
\text { attempted rape }(n=393,200)\end{array}$ & $\begin{array}{l}\text { More likely to help than hurt } \\
\text { in situations of sexual assault }\end{array}$ \\
\hline $\begin{array}{l}\text { Clay-Warner }(2002 ; 2003) \\
\text { Data source: Victimisation data }\end{array}$ & USA & Bystander present during incident & $18 \%$ & $\begin{array}{l}\text { Adult female victims of male- } \\
\text { perpetrated, single offender } \\
\text { rape and attempted rape }(\mathrm{n}=597)\end{array}$ & $\begin{array}{l}\text { Significantly reduced the } \\
\text { probability of completed } \\
\text { rape }\end{array}$ \\
\hline $\begin{array}{l}\text { Beauregard and Leclerc (2007) } \\
\text { Beauregard, Leclerc, Lussier (2012) } \\
\text { Data source: Offender self-report data }\end{array}$ & Canada & $\begin{array}{l}\text { Victim screamed/Witness interference } \\
\text { during incident }\end{array}$ & $30 \%$ & $\begin{array}{l}\text { Male serial stranger rapists } \\
\qquad(\mathrm{n}=30)\end{array}$ & $\begin{array}{l}\text { Associated with rape } \\
\text { avoidance }\end{array}$ \\
\hline $\begin{array}{l}\text { Hart and Miethe (2008) } \\
\text { Data source: Victimisation data }\end{array}$ & USA & Third-party/s present during incident & $28 \%$ & $\begin{array}{l}\text { Victims (aged } 12 \text { and older) of } \\
\text { single offender non-fatal rape } \\
\qquad(\mathrm{n}=384)\end{array}$ & $\begin{array}{l}\text { More likely to help than hurt } \\
\text { in situations of sexual assault }\end{array}$ \\
\hline
\end{tabular}

${ }^{4}$ Defined as "occurrence of an outside intrusion on the assault scene" 


\begin{tabular}{|c|c|c|c|c|c|}
\hline $\begin{array}{l}\text { Guerette and Santana (2010) } \\
\text { Data source: Victimisation data }\end{array}$ & USA & Bystander present during incident & $18.2 \%$ & $\begin{array}{l}\text { Adult female victims of male- } \\
\text { perpetrated, single offender } \\
\text { rape and attempted rape }(\mathrm{n}=782)\end{array}$ & $\begin{array}{l}\text { Significantly reduced the } \\
\text { odds of rape completion }\end{array}$ \\
\hline $\begin{array}{l}\text { Deslauriers-Varin and Beauregard (2010) } \\
\text { Balemba and Beauregard (2013) } \\
\text { Data source: Offender self-report data }\end{array}$ & Canada & Victim alone & $\begin{array}{l}\text { Yes: } 57.6 \% \\
\text { No: } 42.4 \%\end{array}$ & $\begin{array}{l}\text { Male-perpetrated stranger sex } \\
\text { crimes }(\mathrm{n}=361)\end{array}$ & No information provided \\
\hline $\begin{array}{l}\text { Woodhams and Labuschagne, } 2012 \\
\text { Data source: Police files }\end{array}$ & South Africa & Victim alone & $\begin{array}{l}\text { Yes: } 72 \% \\
\text { No: } 28 \%\end{array}$ & $\begin{array}{l}\text { Sexual offenses committed by } \\
\text { male serial rapists }(n=119)\end{array}$ & No information provided \\
\hline $\begin{array}{l}\text { Tark and Kleck (2014) } \\
\text { Data source: Victimisation data }\end{array}$ & USA & Third-party/s present during incident & $20 \%$ & $\begin{array}{l}\text { Adult female victims of rape or } \\
\text { attempted rape }(\mathrm{n}=733) \text {; Adult } \\
\text { female victims of sexual assaults } \\
\text { that were not rapes or } \\
\text { attempted rapes }(\mathrm{n}=1,278)\end{array}$ & $\begin{array}{l}\text { Associated with lower } \\
\text { likelihood of rape } \\
\text { completion }\end{array}$ \\
\hline $\begin{array}{l}\text { Oziel, Goodwill and Beauregard (2014) } \\
\text { Data source : Offender self-report data }\end{array}$ & Canada & Victim alone & $\begin{array}{l}\text { Yes: } 55.6 \% \\
\text { No: } 44.4 \%\end{array}$ & $\begin{array}{l}\text { Male-perpetrated stranger sex } \\
\text { crimes }(\mathrm{n}=147)\end{array}$ & No information provided \\
\hline $\begin{array}{l}\text { Chiu and Leclerc (2016) } \\
\text { Data source: Court transcripts }\end{array}$ & Australia & $\begin{array}{l}\text { Third party/s present initially or during } \\
\text { the incident }\end{array}$ & Almost 50\% & $\begin{array}{l}\text { Make-perpetrated acquaintance } \\
\text { sexual offences }(n=23)\end{array}$ & $\begin{array}{l}\text { Relatively rare for third } \\
\text { parties to intervene or disrup } \\
\text { the crime. }\end{array}$ \\
\hline
\end{tabular}


Table 2: Descriptive statistics for the sample of sexual offences involving adult female victims $(n=138)$

\begin{tabular}{lc}
\hline Variables & Percentage $(n)$ \\
\hline $\begin{array}{l}\text { Dependent variable } \\
\text { Offence was disrupted }\end{array}$ & $45.7(63)$ \\
Independent variables & $35.5(49)$ \\
Guardianship* & $\mathbf{6 5 . 3 ( 3 2 )}$ \\
Nearby & $\mathbf{2 . 0}(\mathbf{1})$ \\
Witness & $\mathbf{3 2 . 7}(\mathbf{1 6})$ \\
Intervention & $50.0(69)$ \\
Victim is a stranger & $55.1(76)$ \\
Offence occurred indoors & $52.2(72)$ \\
Victim resisted either verbally or physically & \\
\hline
\end{tabular}

* Three participants reported the presence of a person who witnessed and intervened and a person nearby during their most recent offence. For these three events, guardianship was coded according to the highest intensity that was reported - i.e. intervention. 
Table 3: Dominant situational contexts for the disruption of a sexual offence against an adult woman $(n=138)$

\begin{tabular}{|c|c|c|c|c|c|c|c|}
\hline $\begin{array}{c}\text { Configuration } \\
\text { number }\end{array}$ & Guardianship & $\begin{array}{c}\text { Victim } \\
\text { resistance }\end{array}$ & Relationship & Location & $N$ & $\begin{array}{c}\text { Percent } \\
\text { disrupted }\end{array}$ & Likelihood $^{5}$ \\
\hline $\mathbf{1}$ & Yes & Yes & Non-stranger & Outdoors & $\mathbf{7}$ & $\mathbf{1 0 0}$ & High \\
\hline $\mathbf{2}$ & Yes & Yes & Stranger & Outdoors & $\mathbf{6}$ & $\mathbf{8 3}$ & High \\
\hline $\mathbf{3}$ & No & Yes & Non-stranger & Outdoors & $\mathbf{5}$ & $\mathbf{8 0}$ & High \\
\hline $\mathbf{4}$ & Yes & No & Stranger & Outdoors & $\mathbf{6}$ & $\mathbf{6 7}$ & High \\
\hline $\mathbf{5}$ & No & Yes & Stranger & Indoors & $\mathbf{1 4}$ & $\mathbf{6 4}$ & High \\
\hline 6 & No & Yes & Stranger & Outdoors & 16 & 54 & Medium \\
\hline 7 & No & Yes & Non-stranger & Indoors & 14 & 50 & Medium \\
\hline 8 & Yes & No & Non-stranger & Indoors & 16 & 44 & Medium \\
\hline 9 & Yes & Yes & Non-stranger & Indoors & 7 & 29 & Low \\
\hline 10 & No & No & Stranger & Outdoors & 14 & 14 & Low \\
\hline 11 & No & No & Non-stranger & Outdoors & 7 & 0 & Low \\
\hline 12 & No & No & Non-stranger & Indoors & 12 & 0 & Low \\
\hline 13 & No & No & Stranger & Indoors & 6 & 0 & Low \\
\hline
\end{tabular}

\footnotetext{
${ }^{5} \mathrm{High}=$ at least 10 per cent above the average likelihood of 45.1 percent; Medium =within 10 per cent of the average likelihood, Low=at least 10 per cent below the average likelihood of 45.1 per cent.
} 
Table 4: Logistic regression models of guardianship and offence characteristics on disrupted sexual offence outcome $(n=138)$

\begin{tabular}{|c|c|c|}
\hline Variable & $\begin{array}{c}\text { Model } 1 \\
b(\mathrm{SE}) \\
\Psi\end{array}$ & $\begin{array}{c}\text { Model } 2 \\
b(\mathrm{SE}) \\
\Psi\end{array}$ \\
\hline Guardianship $^{6}$ & $\begin{array}{c}1.18(.370) \\
3.27 * * *\end{array}$ & $\begin{array}{c}1.81(.464) \\
6.08 * * *\end{array}$ \\
\hline Victim resistance $e^{7}$ & - & $\begin{array}{c}1.93(.434) \\
6.85^{* * *}\end{array}$ \\
\hline Stranger relationship ${ }^{8}$ & - & $\begin{array}{c}.501(.432) \\
1.65\end{array}$ \\
\hline Offence occurred indoors ${ }^{9}$ & - & $\begin{array}{c}-.47(.427) \\
.63\end{array}$ \\
\hline
\end{tabular}

$b=$ Unstandardized beta; $\mathrm{SE}=\mathrm{Standard}$ error; $\Psi=$ Odds ratio.

Note $* * * \mathrm{p} \leq .001$

\footnotetext{
${ }^{6}$ Reference category is Yes - Guardian present

${ }^{7}$ Reference category is Yes - Victim resistance

${ }^{8}$ Reference category is Yes - Stranger

${ }^{9}$ Reference category is Yes - Indoors
} 
Table 5: Chi-square for offence characteristics, by sexual offence outcome $(n=49)$

\begin{tabular}{lccc}
\hline Variable & $\chi^{2}$ & $\mathrm{df}$ & Sig. \\
\hline High-intensity guardianship ${ }^{10}$ & 8.72 & 1 & $.003^{* * *}$ \\
Victim resistance & 0.61 & 1 & .435 \\
Stranger relationship & 2.58 & 1 & .112 \\
Offence occurred outside & 5.86 & 1 & $.015^{* *}$ \\
\hline
\end{tabular}

Note $* * \mathrm{p} \leq .01, * * * \mathrm{p} \leq .001$

${ }^{10}$ High intensity' guardianship was defined as guardians who witnessed and/or intervened 
Figure 1: Characteristics of guardians available in disrupted offences $(n=63)$

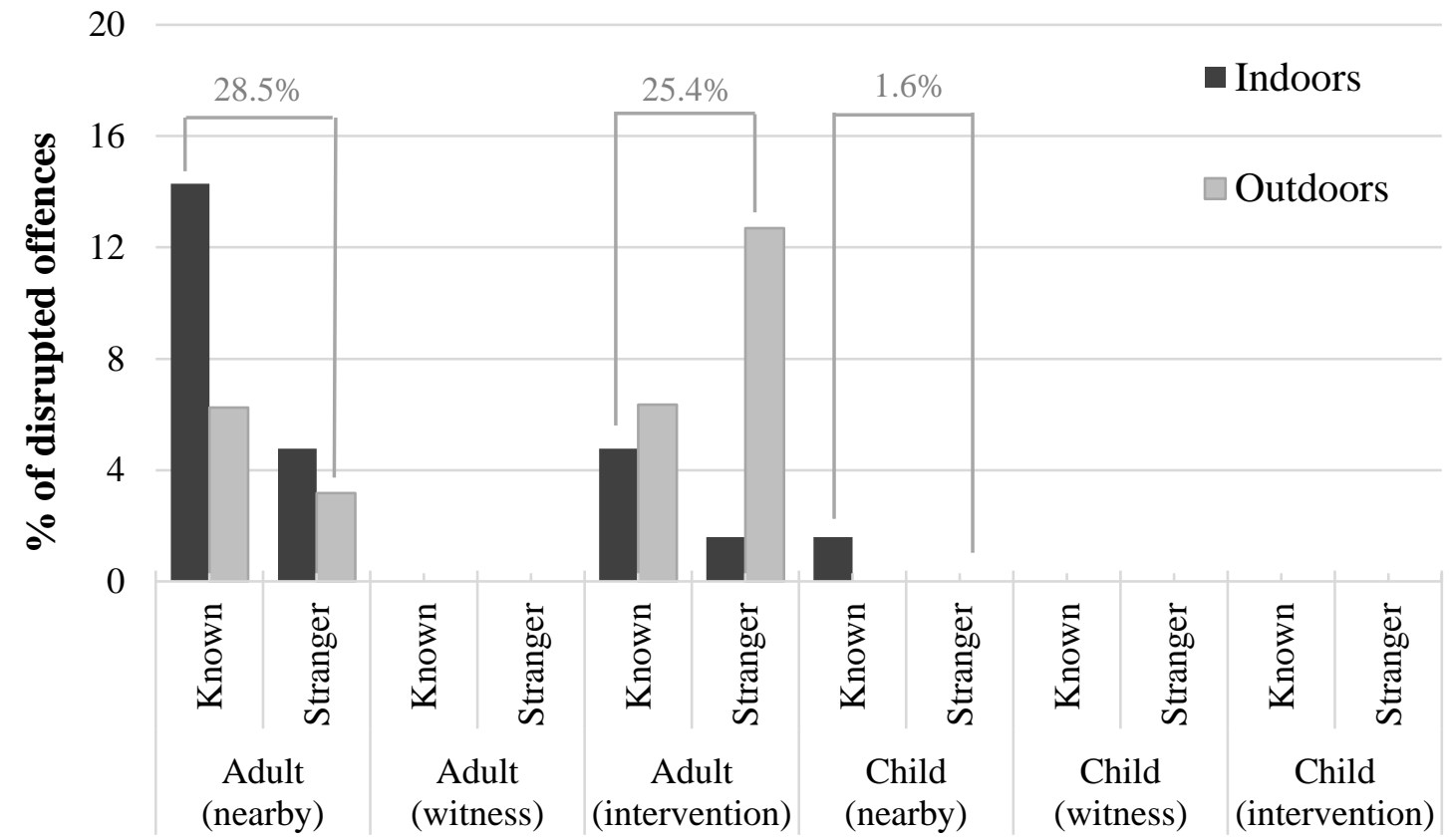

Characteristics of guardians 
Figure 2: Characteristics of guardians available in completed offences $(n=75)$

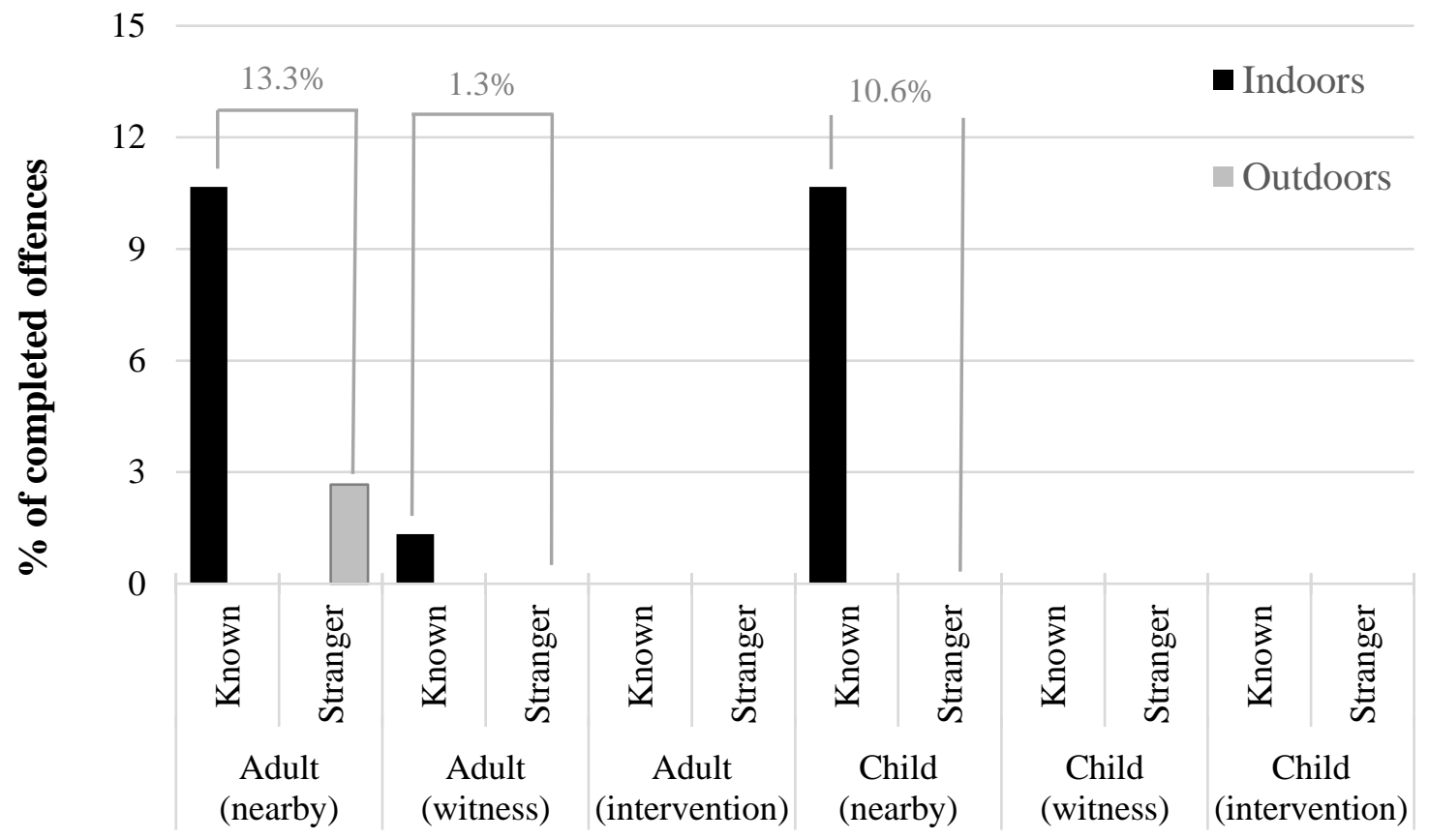

Characteristics of guardians 
Figure 3: Guardianship intensity according to outcome of crime event $(n=138)$

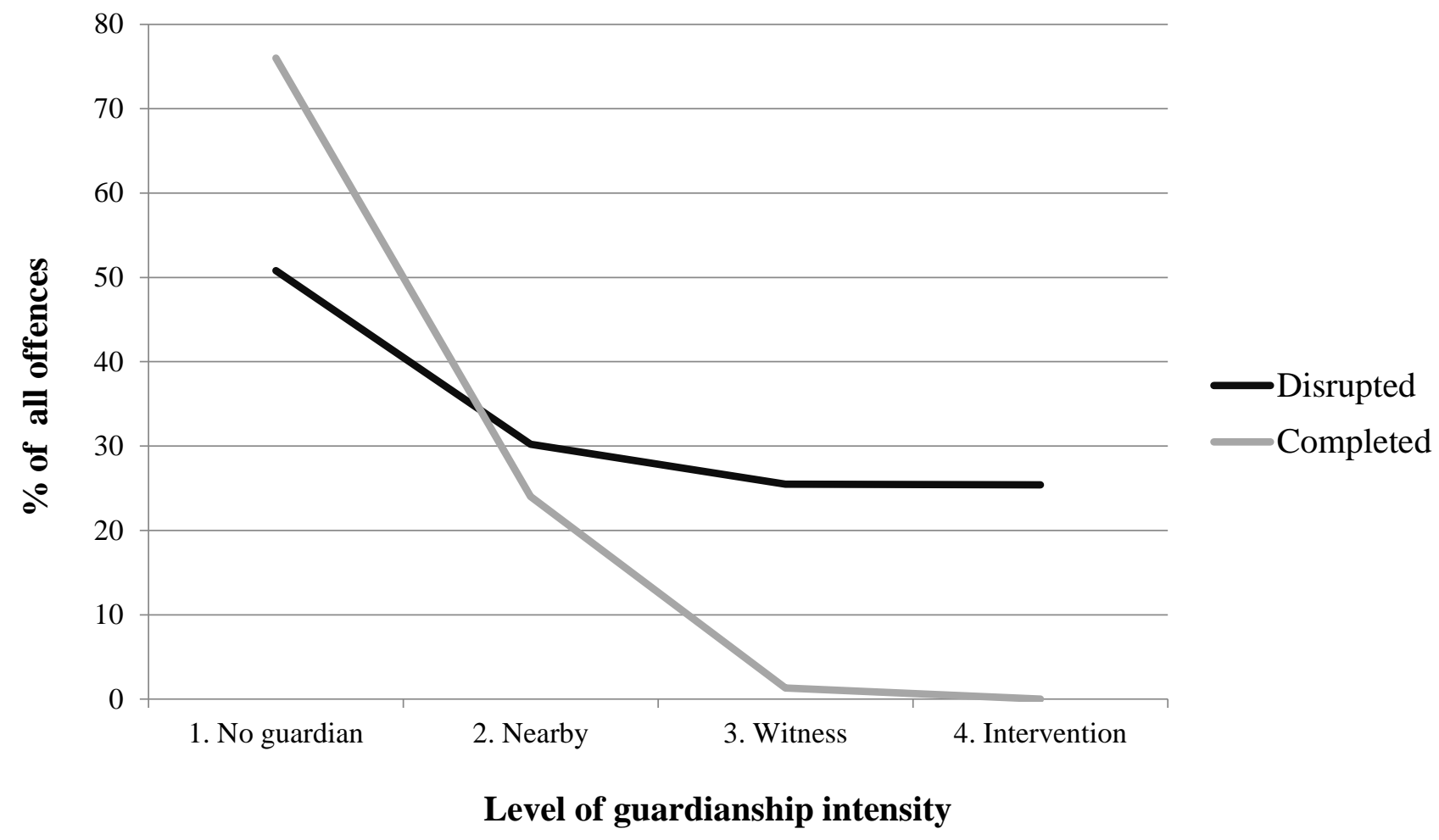


Figure 4: Reactions of witnesses to sexual contact $(n=17)$

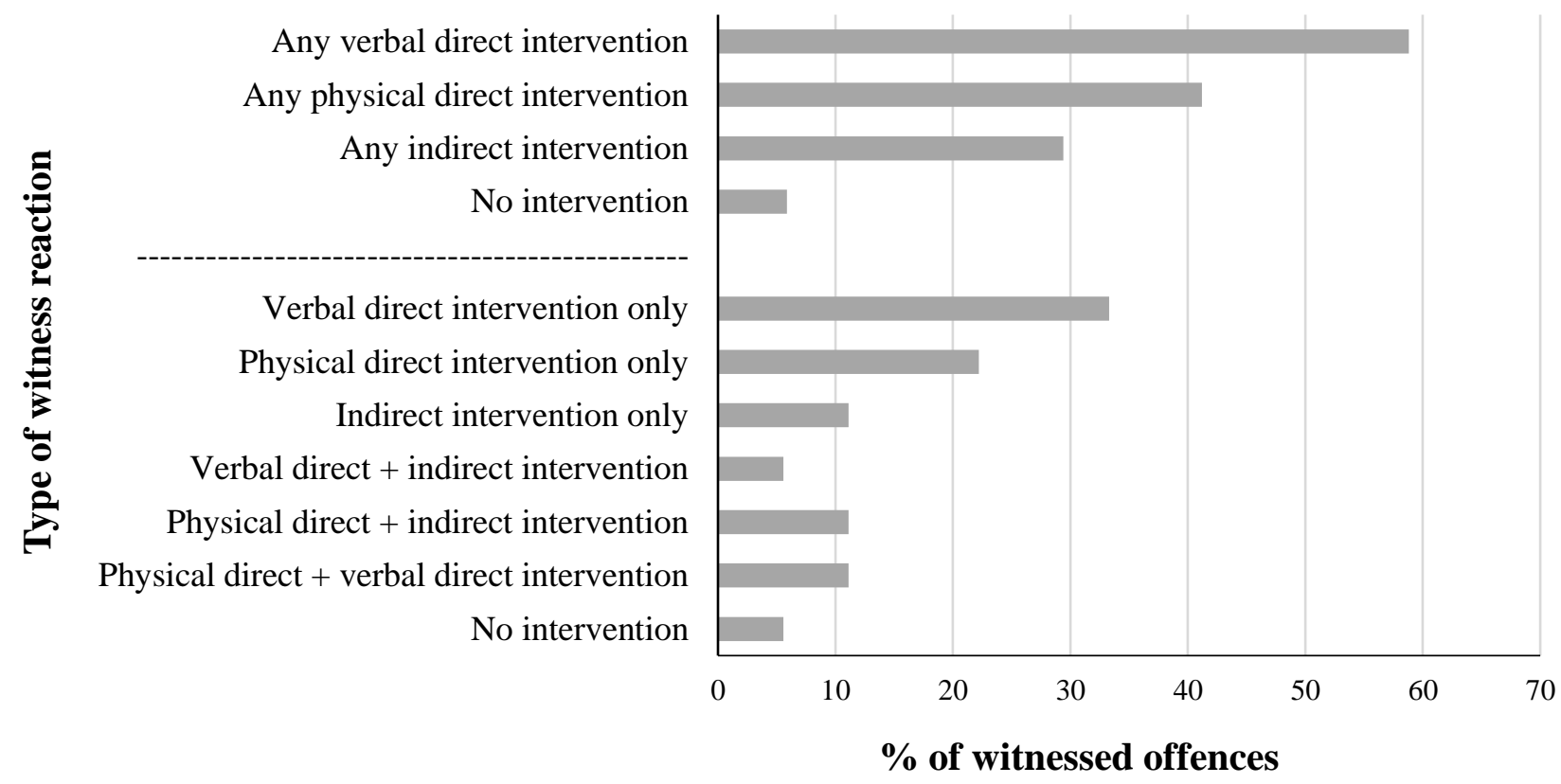

